\title{
Psidin, a conserved protein that regulates protrusion dynamics and cell migration
}

\author{
Ji Hoon Kim, ${ }^{1}$ Aeri Cho, ${ }^{1}$ Hongyan Yin ${ }^{1}$ Dorothy A. Schafer, ${ }^{2,3}$ Ghassan Mouneimne, ${ }^{4}$ \\ Kaylene J. Simpson, ${ }^{4}$ Kim-Vy Nguyen, ${ }^{4}$ Joan S. Brugge, ${ }^{4}$ and Denise J. Montell ${ }^{1,5}$ \\ ${ }^{1}$ Department of Biological Chemistry, Center for Cell Dynamics, Johns Hopkins School of Medicine, Baltimore, Maryland 21205, \\ USA; ${ }^{2}$ Department of Biology, University of Virginia, Charlottesville, Virginia 22904, USA; ${ }^{3}$ Department of Cell Biology, \\ University of Virginia, Charlottesville, Virginia 22904, USA; ${ }^{4}$ Department of Cell Biology, Harvard Medical School, Boston, \\ Massachusetts 02115, USA
}

\begin{abstract}
Dynamic assembly and disassembly of actin filaments is a major driving force for cell movements. Border cells in the Drosophila ovary provide a simple and genetically tractable model to study the mechanisms regulating cell migration. To identify new genes that regulate cell movement in vivo, we screened lethal mutations on chromosome 3R for defects in border cell migration and identified two alleles of the gene psidin (psid). In vitro, purified Psid protein bound F-actin and inhibited the interaction of tropomyosin with F-actin. In vivo, psid mutations exhibited genetic interactions with the genes encoding tropomyosin and cofilin. Border cells overexpressing Psid together with GFP-actin exhibited altered protrusion/retraction dynamics. Psid knockdown in cultured S2 cells reduced, and Psid overexpression enhanced, lamellipodial dynamics. Knockdown of the human homolog of Psid reduced the speed and directionality of migration in wounded MCF10A breast epithelial monolayers, whereas overexpression of the protein increased migration speed and altered protrusion dynamics in EGF-stimulated cells. These results indicate that Psid is an actin regulatory protein that plays a conserved role in protrusion dynamics and cell migration.
\end{abstract}

[Keywords: cell migration; Drosophila; genetics; protrusion; actin, tropomyosin]

Supplemental material is available for this article.

Received January 4, 2011; revised version accepted February 11, 2011.

Cell motility is essential for many biological processes, such as embryonic development, immune responses, and wound healing. It is a complex, integrated process, requiring changes in gene expression, signal transduction, membrane organization, and the cytoskeleton (Ridley et al. 2003). The signals regulating cell migration need to be precisely controlled because inappropriate cell migration can result in pathological conditions such as inflammation or tumor invasion (Naora and Montell 2005).

The actin cytoskeleton provides the mechanical frame for the force-generating machinery necessary for cells to move. As they move, cells extend protrusions in the direction of movement through the combination of actin filament assembly and disassembly. Cellular adhesions link intracellular F-actin with the extracellular substratum and function as traction sites and mechanosensors. The interaction of myosin motors and actin filaments generates the traction force necessary for cells to move forward (for review, see Ridley et al. 2003; Chhabra and Higgs 2007).

${ }^{5}$ Corresponding author.

E-MAIL dmontell@jhmi.edu; FAX (410) 955-5759.

Article published online ahead of print. Article and publication date are online at http://www.genesdev.org/cgi/doi/10.1101/gad.2028611.
The leading edge of a migrating cell shows particularly dynamic construction and destruction of the actin network, facilitated by a variety of proteins (for review, see Cooper and Schafer 2000; Pollard and Borisy 2003). For example, cofilin severs actin filaments, which can enhance filament depolymerization but also creates new barbed ends, and thus stimulates actin polymerization when monomer concentration is high (Ichetovkin et al. 2002; Adrianantoandro and Pollard 2006). Behind the leading edge, tropomyosin dimers coat the sides of actin filaments, protecting them from cofilin. Thus, the precise actin dynamics in a particular cell type or a particular region of a cell depend on the relative concentrations of actinbinding proteins such as cofilin and tropomyosin. Even though numerous proteins controlling actin dynamics have been identified, it is unclear whether all of the genes and proteins that contribute to actin dynamics and cell motility have been identified, or whether some important activities might have gone undetected.

Border cell migration in the Drosophila ovary provides a well-developed genetic model system to address this question. During Drosophila oogenesis, a group of six to 10 epithelial cells, the border cells, detaches from its neighbors and migrates in between nurse cells to the 
oocyte (Fig. 1A-C; for review, see Rørth 2002; Montell 2003). Border cells extend cellular protrusions enriched with actin during the migration (Murphy and Montell 1996; Fulga and Rørth 2002; Prasad and Montell 2007). Furthermore, mutations in key actin-regulating proteins such as the GTPase Rac, profilin, and cofilin cause border cell migration defects (Verheyen and Cooley 1994; Murphy and Montell 1996; Chen et al. 2001; Geisbrecht and Montell 2004). Therefore, regulation of the actin cytoskeleton is critical for proper border cell migration.

In this study, we report the identification and characterization of a novel F-actin-binding protein, Psidin (pronounced "sigh-din" and abbreviated Psid). psid mutations caused border cell migration defects in vivo. Altering Psid expression affected protrusion dynamics in border cells and Drosophila S2 cells. Moreover, altering the level of expression of the human Psid homolog affected protru-
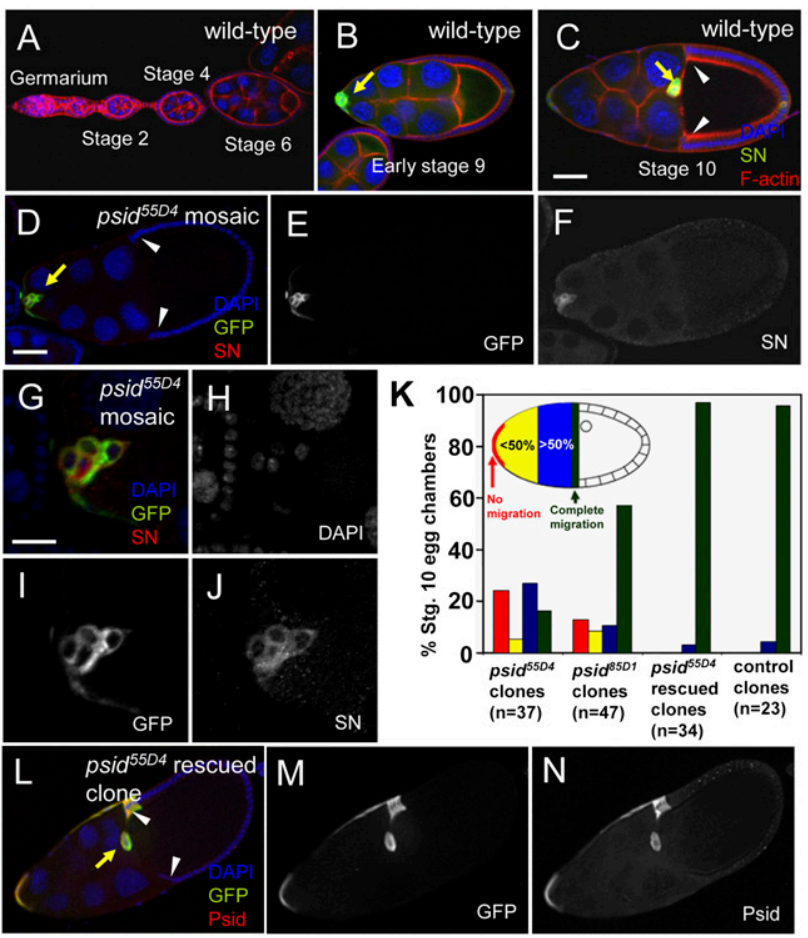

SN

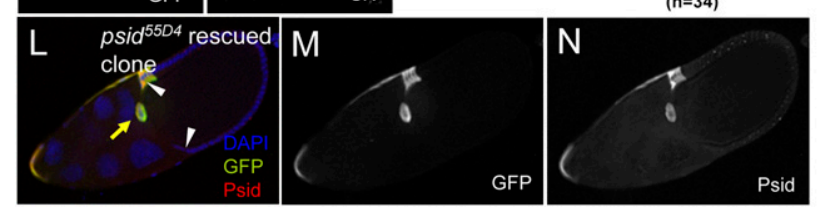

Figure 1. A new border cell migration mutant. $(A-C)$ Wild-type egg chambers of the indicated stages showing border cell (yellow arrows) development and migration to the oocyte. $(D-N)$ Phenotype of $p s i d^{55 D 4}$ mutant clones in the absence $(D-K)$ or presence $(K-N)$ of a rescuing transgene. Homozygous mutant cells are labeled with GFP. $(D-J)$ The border cell marker Singed $(\mathrm{SN})$ is labeled in red in $D$ and $G$ and white in $F$ and $J$. $E$ and $I$ show the GFP channel alone. $(G-J)$ High-magnification views of the mutant cluster shown in $D-F$. $(K)$ Histogram summarizing the migration defects found in the indicated numbers $(n)$ of egg chambers containing border cells mutant for two different alleles of psid. $(L-N)$ Rescue of the psid ${ }^{55 D 4}$ phenotype. $(L, M)$ Homozygous mutant clones expressing GFP were generated with UAS-psid transgene in the background (see the Materials and Methods for details). Anti-Psid antibody staining is shown in $N$. Arrowheads indicate the border between the oocyte and nurse cells. Bars: $C, D, 50 \mu \mathrm{m} ; G, 10 \mu \mathrm{m}$. sive behavior of mammalian MCF10A cells, as well as the speed and directionality of their movement. These results suggest that Psid plays a conserved role in the regulation of protrusion dynamics and cell migration.

\section{Results}

\section{Psid is required for border cell migration}

In order to find mutations affecting border cell migration, an EMS mutagenesis screen of the right arm of the third chromosome was performed (Silver and Montell 2001). We selected two mutant alleles, 55D4 and 85D1, which failed to complement each other for lethality. In contrast to control stage 10 egg chambers, in which border cells have invariably reached the oocyte (Fig. 1C), border cells frequently did not leave the anterior end of the egg chamber at all in egg chambers containing clones of homozygous mutant cells (Fig. 1D-F). Mutant border cells were specified normally because border cell-enriched proteins such as Singed (SN) and SLBO were expressed at normal levels (Fig. 1J; data not shown). Thus, the migration defect did not result from a defect in cell fate determination. To quantify the border cell migration defect, the extent of migration was measured for border cell clusters in which all cells were mutant (Fig. 1K). More than $80 \%$ of border cell clusters mutant for the 55D4 allele failed to reach the oocyte by stage 10 , whereas $25 \%$ of clusters homozygous for the $85 \mathrm{D} 1$ allele were defective.

Both alleles contained a lethal mutation that mapped to the 92C1-92D4 region based on meiotic recombination and deficiency mapping. One Piggybac insertion line, e02846, failed to complement each EMS mutant for lethality. This transposon is inserted in the second intron of CG4845 (Supplemental Fig. S1A). A previous study identified CG4845 as a gene required for the innate immune response and named the gene psid (Brennan et al. 2007). Re-expression of Psid protein from a transgene in homozygous mutant border cells restored normal migration (Fig. $1 \mathrm{~K}-\mathrm{N})$. In addition, the lethality of $\mathrm{psid}^{55 D 4} / \mathrm{psid}^{85 D 1}$ flies was rescued by actin-Gal4,UAS-psid (data not shown).

psid is predicted to encode a protein of 948 amino acids (Supplemental Fig. S1). Both $p s i d^{55 D 4}$ and $p s i d^{85 D 1}$ contained nonsense mutations: $p s i d^{55 D 4}$ at residue 471 , and psid $^{85 D 1}$ at residue 807 (Supplemental Fig. S1A). RT-PCR and cDNA sequencing showed a single detectable transcript in the ovary, which encoded the same amino acid sequence as predicted (data not shown). The predicted Psid protein has two recognizable sequence motifs: a tetratricopeptide repeat (TPR) at its $\mathrm{N}$ terminus, and a pair of coiledcoil motifs at its $\mathrm{C}$ terminus (Supplemental Fig. S1B). The TPR motif is thought to mediate protein-protein interactions in diverse protein families (Blatch and Lassle 1999; D'Andrea and Regan 2003). Interestingly, the stronger allele 55D4 causes truncation of the protein prior to both coiled-coil domains, whereas the weaker allele 85D1 could, in principle, allow expression of a truncated protein that would retain one coiled-coil domain. There is a single psid homolog encoded in the genomes of most organisms, including humans (Brennan et al. 2007; Smolikov et al. 
2008). The fly and human proteins share an average of $31 \%$ amino acid identity (BLAST $\mathrm{E}$ value $=2 \mathrm{e}^{-117}$ ), distributed through the whole protein length (Supplemental Fig. S1C). The sequence identity is higher (44\%) within the TPR domain.

\section{Widespread psid expression in egg chambers}

To determine the expression pattern of psid in the egg chamber, we performed mRNA in situ hybridization and antibody staining. An antisense RNA probe labeled germline cells strongly. Border cells and outer follicle cells also showed Psid mRNA expression (Fig. 2A,B). An antibody against a C-terminal peptide labeled all cell types, consistent with the mRNA expression, and the protein appeared cytoplasmic (Fig. 2C,D). When we stained egg chambers from slbo-Gal4; UAS-psid transgenic flies, the antibody recognized the overexpressed protein in border cells, centripetal cells, and posterior follicle cells, as expected (Fig. $2 \mathrm{E}, \mathrm{F})$. In addition, psid mutant cells in mosaic clones showed a decreased level of immunoreactivity compared with neighboring wild-type cells (Fig. 2G-I). Expression data in FlyBase (http://flybase.org/reports/FBgn0243511.html) indicates that, in the adult, Psid mRNA expression is widespread and highest in ovary and testis, whereas in larvae it is highest in the CNS and trachea.

\section{psid mutations cause defects in multiple cell types}

To investigate the function of the psid gene further, we examined loss-of-function phenotypes caused by psid

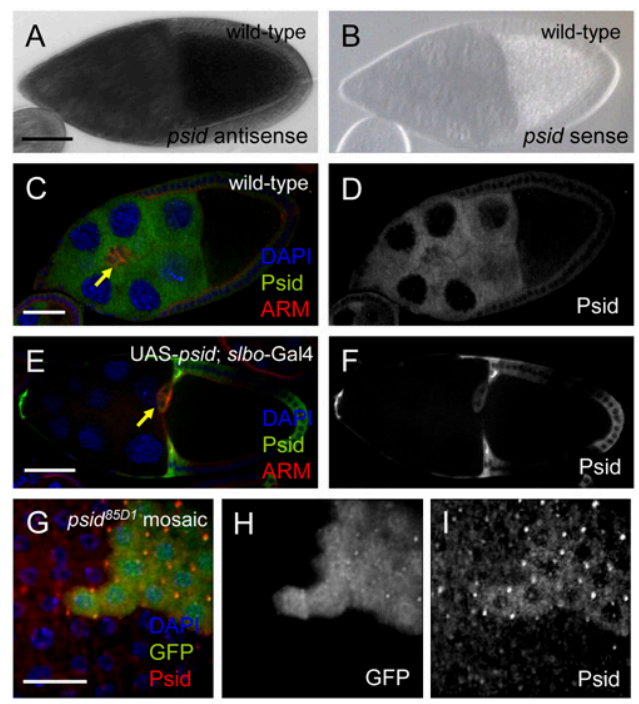

Figure 2. Psid mRNA and protein expression. $(A, B)$ In situ hybridization of late stage 9 egg chambers using antisense $(A)$ or sense $(B)$ strand probes. $(C)$ Anti-Psid antibody staining (green) of a wild-type stage 9 egg chamber. (E) Overexpression of Psid using slbo-Gal4 and UAS-psid transgenes. DAPI (blue) labels DNA, and ARM (red) labels cell membranes. $(G-I)$ Mosaic follicle cells showing homozygous wild-type cells (GFP-positive, green in $G$, white in $H$ ) and homozygous mutant (GFP-negative) cells. $(D, F, I)$ Same egg chambers as in $C, E$, and $G$, respectively, showing Psid channel only. Bars: $A, C, E, 50 \mu \mathrm{m} ; G, 10 \mu \mathrm{m}$. mutations in additional egg chamber cell types. In addition to border cell migration defects, we observed multinucleated cells in large clones within the follicular epithelium (Supplemental Fig. S2A,B). This phenotype may be due to a defect in cytokinesis, which, like cell migration, requires actin cytoskeleton dynamics. psid mutant follicle cells also frequently formed multiple layers, particularly at the posterior pole, instead of the monolayer found in wild-type egg chambers (Supplemental Fig. S2C,D). Multilayering of the follicular epithelium has been described for mutations affecting actin regulatory proteins, such as the Abelson kinase (Baum and Perrimon 2001), or cell polarity proteins, such as Discs large (Goode and Perrimon 1997).

Disruption of psid function in nurse cells enabled us to observe phenotypes related to the actin cytoskeleton more clearly because of their large size. In mutant (GFP-negative) nurse cells, phalloidin staining, which labels F-actin specifically, was brighter than in adjacent wild-type (GFP-positive) cells (Supplemental Fig. S2E-H). Excess F-actin accumulated predominantly at the cell cortex, which appeared irregular and distorted relative to the smooth contours of wild-type cells (Supplemental Fig. S2H). Overexpression of Psid in nurse cells reduced phalloidin staining intensity compared with controls stained in parallel (Supplemental Fig. S2I-L). In cultured S2 cells, overexpression of Psid also resulted in a reduction in the overall level of phalloidin staining intensity and altered the distribution of F-actin (Supplemental Fig. S3). These findings indicate that Psid influences the level and organization of F-actin.

\section{Effect of Psid on protrusion dynamics in S2 cells}

To explore the effects of Psid on actin cytoskeleton dynamics, we knocked down Psid expression in cultured Drosophila S2 cells by RNAi (Fig. 3A) and evaluated the effect on membrane ruffling and protrusion by time-lapse microscopy. Control cells expressing EGFP-actin alone showed, on average, eight membrane ruffles over a 10-min interval (Fig. 3B,E; Supplemental Movie S1). In contrast, cells in which Psid was knocked down had, on average, only one ruffle every $10 \mathrm{~min}$ (Fig. 3C,E; Supplemental Movie S2). Cells overexpressing Psid exhibited an average of 17 dorsal ruffles in $10 \mathrm{~min}$ (Fig. 3D,E; Supplemental Movie S3). The dynamic region around the periphery of the cell is referred to as the lamellipodium (Iwasa and Mullins 2007). We noticed that the lamellipodium was narrower in Psid knockdown cells and wider following Psid overexpression (Fig. 3F). The rate of rearward flow of EGFPactin within lamellipodia was also significantly lower in Psid knockdown cells (Fig. 3G), suggesting reduced lamellipodial actin dynamics.

To examine lamellipodial dynamics in more detail, we carried out a kymography analysis (Fig. 3H-J). A kymograph depicts the movement of the cell membrane at one position over time and allows a number of parameters to be quantified. Compared with the control, Psid knockdown cells showed less overall protrusive activity, whereas Psid-overepressing cells protruded farther (Fig. $3 \mathrm{H}-\mathrm{K}$ ). Moreover, Psid-overexpressing cells exhibited significantly higher rates of protrusion and retraction compared 
A

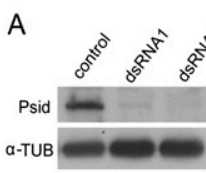

$\mathrm{E}_{\overline{\mathrm{g}}}$

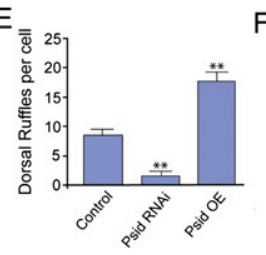

$\mathrm{H}$
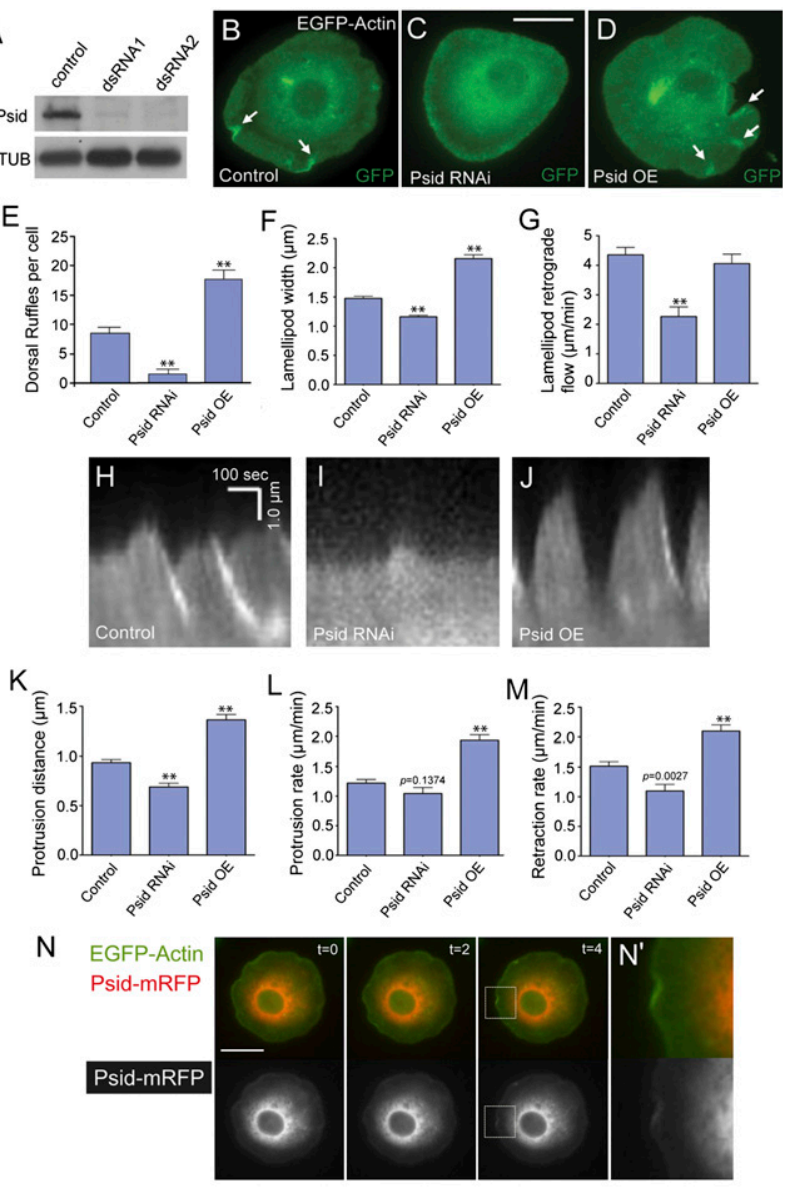

O
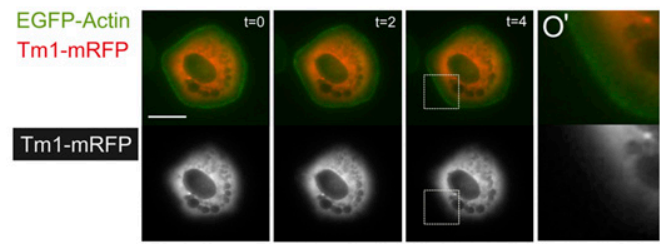

Figure 3. Psid regulation on protrusion dynamics in $\mathrm{S} 2$ cells. (A) Western blots of S2 cell lysates with or without dsRNA treatment to knock down Psid expression. dsRNA1 and dsRNA2 target the $5^{\prime}$ untranslated region (UTR) and fifth exon of Psid mRNA, respectively. $\alpha$-Tubulin was used as a loading control. $(B-D)$ Fluorescence micrographs of EGFP-actin-expressing S2 cells. (B) A control cell expressing EGFP-actin alone. Arrows indicate ruffles. $(C)$ A Psid knockdown cell. Note the absence of ruffles. Bar, $10 \mu \mathrm{m}$. (D) A cell overexpressing (OE) Psid. Note the more spread morphology and extra ruffles. Magnification is the same in all three panels. $(E-G)$ Bar graphs showing quantification of the indicated parameters measured in control, Psid knockdown, and Psid-overexpressing cells. $(H-J)$ Kymographs of EGFP-actin-expressing cells. A line was drawn perpendicular to the cell surface; that line is shown for each frame of a time-lapse movie and shows the dynamics of the cell edge over time. The $X$-axis represents time. $(K-M)$ Quantification of edge dynamics from kymographic analysis (see the Materials and Methods for details). Error bars represent SEMs. $\left(^{\star \star}\right) P<.0001$. $(N, O)$ Time-lapse images of an S2 cell overexpressing RFP-tagged Psid or Tm1 (red in the top panels and white in the bottom panels). Bars, $10 \mu \mathrm{m} . N^{\prime}$ and $O^{\prime}$ show enlarged pictures corresponding to boxed areas in $t=4$ pictures. Time scale is shown in minutes. with the control (Fig. 3L,M). Additionally, overexpressed Psid-mRFP localized to areas of dynamic actin reorganization at the cell edge that were visualized by the increase in EGFP-actin using live-cell imaging (Fig. $\left.3 \mathrm{~N}^{\prime} \mathrm{N}^{\prime}\right)$. In contrast, Tm1-mRFP was excluded from these areas at the edge (Fig. 30, $\mathrm{O}^{\prime}$ ). Tropomyosin stabilizes actin structures in the lamellum, the region behind the lamellipodium, and is absent from the lamellipodium (Ponti et al. 2004). Together, these results indicate that Psid promotes lamellipodial protrusion/retraction dynamics.

\section{Altered protrusion dynamics in border cells overexpressing Psid and EGFP-actin}

To investigate Psid function in protrusion dynamics during border cell migration, Psid was overexpressed together with EGFP-actin, and border cell migration and morphology were analyzed. Border cells normally extend and retract actin-rich protrusions dynamically during their migration (Prasad and Montell 2007). EGFP-actin is incorporated into actin filaments and labels the cytoplasm and protrusions (Fulga and Rørth 2002). Border cells overexpressing Psid and EGFP-actin at $29^{\circ} \mathrm{C}$ exhibited longer protrusions than cells expressing EGFP-actin alone (Fig. 4A,B; Table 1). Furthermore, the protrusions were highly abnormal in morphology, as they were elongated, irregular in length, of variable thickness, and even branched (Fig. 4A,B; Supplemental Movie S4). Conversely, protrusions were shorter than the control in border cells heterozygous for the $p s i d^{55 D 4}$ allele (Table 1). Even though neither
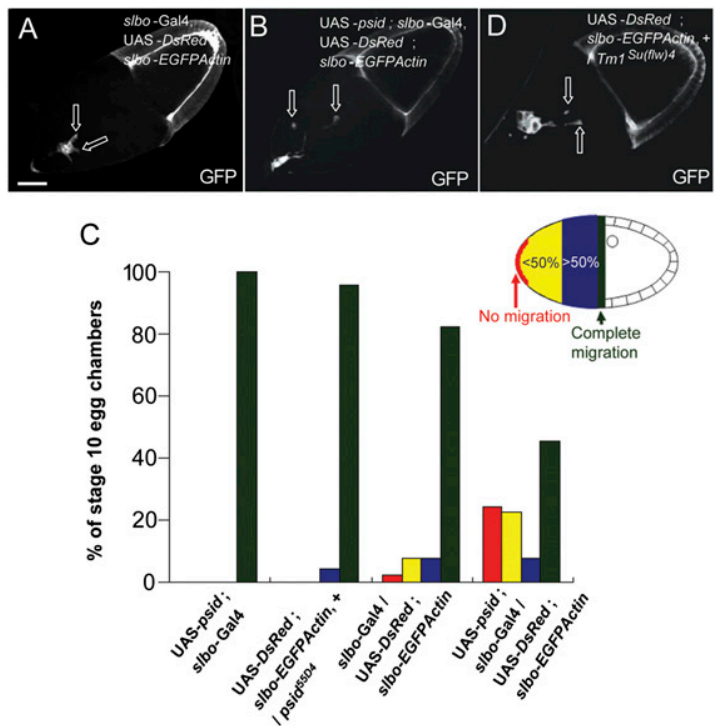

Figure 4. Effect of Psid and EGFP-actin overexpression on border cell protrusion dynamics. $(A, B, D)$ Late stage 9 egg chambers expressing EGFP-actin directly under the control of slbo regulatory sequences. $(A)$ Control of the indicated genotype. $(B)$ Psid overexpression in border cells. $(C)$ Histogram summarizing stage 10 migration defects in the indicated genotypes. $(D)$ Egg chamber heterozygous for $\operatorname{Tm} 1^{\mathrm{Su}\left(f f_{w}\right) 4}$. Arrows indicate the tips of long protrusions. In $A, B$, and $D$, GFP channel alone is shown. Bar, $50 \mu \mathrm{m}$. 
Table 1. Effect of Psid overexpression on border cell protrusion length

\begin{tabular}{|c|c|c|c|c|}
\hline Phenotype & $\begin{array}{l}\text { slbo-Gal4/UAS- } \\
\text { DsRed; slbo- } \\
\text { EGFPActin }\end{array}$ & $\begin{array}{l}\text { UAS-psid; slbo- } \\
\text { Gal4/UAS-DsRed; } \\
\text { slbo-EGFPActin }\end{array}$ & $\begin{array}{l}\text { UAS-DsRed; slbo- } \\
\text { EGFPActin, } \\
\text { +/psid }\end{array}$ & $\begin{array}{c}\text { UAS-DsRed; slbo- } \\
\text { EGFPActin, } \\
+/ T m 1^{\text {Sulfflw)4 }}\end{array}$ \\
\hline Number of clusters with abnormal protrusion/total & $2 / 13$ & $10 / 13$ & $3 / 20$ & $10 / 14$ \\
\hline Number of protrusions per cluster & $1.8( \pm 1.4)$ & $1.9( \pm 1.0)$ & $1.7( \pm 1.0)$ & $1.9( \pm 1.2)$ \\
\hline Average length of protrusions $(\mu \mathrm{m})$ & $27.8( \pm 12.3)$ & $44.8( \pm 33.6)$ & $15.8( \pm 10.0)$ & $35.9( \pm 18.2)$ \\
\hline
\end{tabular}

Numbers in parentheses are the standard deviations.

Psid nor EGFP-actin resulted in a severe migration defect on its own, coexpression of Psid and EGFP-actin resulted in dramatic inhibition of border cell movement (Fig. 4C).

To study the dynamic effects of Psid overexpression, time-lapse imaging of migrating border cells was carried out in the presence of EGFP-actin, with or without Psid overexpression. During migration, border cells expressing EGFP-actin alone exhibited dynamic extension and retraction of protrusions (Supplemental Movie S5). Protrusions in the direction of migration are more numerous, longer, and longer-lived than protrusions in other directions (Prasad and Montell 2007). Border cells overexpressing Psid also extended protrusions toward the oocyte. However, Psid-overexpressing border cells did not retract protrusions effectively, in contrast to control cells (Supplemental Movie S6). Protrusions kept growing and became longer, thinner, and sometimes branched and even fragmented, which we have never observed in controls. Several observations indicated that this phenotype was not an indirect consequence of the inability of the cells to move away from the anterior. First, wild-type border cells typically extend and retract multiple protrusions prior to moving away from the anterior, so retraction does not require that the cells move forward. Second, other perturbations that prevent forward movement, such as expression of dominant-negative Kuz, do not cause this phenotype. Third, we observed examples of border cells overexpressing Psid and EGFP-actin in which the cells detached from the anterior but still extended extra-long and abnormal protrusions.

\section{Biochemical properties of Psid}

The effects on protrusion dynamics suggested that Psid might interact directly with actin filaments (Cooper and Schafer 2000; Ono 2007). To determine if Psid bound to F-actin, we performed cosedimentation assays with purified Psid protein and found a fraction of Psidin protein cosedimented with F-actin (Fig. 5A,B). To determine if Psid directly influences actin polymerization or depolymerization, we examined assembly of pyrenyl-actin from F-actin seeds (FAS) or nucleated by Arp2/3 complex. Psid did not alter the rate of actin assembly from FAS or de novo actin nucleation by Arp $2 / 3$ complex; thus, it does not cap actin filaments, sequester G-actin, or influence the rate of filament elongation (Fig. 5D,E). Psid also did not directly alter the actin filament-severing activity of cofilin when assessed using pyrenyl-actin assembly from cofilin-treated FAS (Fig. 5F) or by TIRF microscopy (data not shown).
The predicted coiled-coil domains in the $\mathrm{C}$ terminus suggested that Psid protein might form multimers. To test this hypothesis, we carried out coimmunoprecipitation assays. Psid protein tagged with a V5 epitope coimmunoprecipitated with HA-tagged protein and vice versa (Fig. 5C). This suggests that Psid likely functions as a multimer. However, Psid did not bundle actin filaments (data not shown), suggesting that multimers of Psid bind the sides of F-actin but do not cross-link actin filaments.

\section{Interactions between Psid and Tropomyosin}

Since Psid bound actin filaments, we tested for genetic interactions between Psid and other genes encoding actin regulatory proteins. Psid was overexpressed in border cells using slbo-Gal4 (without EGFP-actin) at $32^{\circ} \mathrm{C}$ in otherwise wild-type flies, or in flies that were heterozygous for mutations in genes encoding a variety of actin regulatory proteins (Table 2). Whereas most mutations showed little or no effect on border cell migration in this assay, mutations in Tropomyosin1 (Tm1) caused border cell migration defects in $27 \%-50 \%$ of stage 10 egg chambers examined (Table 2). About $10 \%$ of $T m 1^{P Z 2299} /+$ or $T m 1^{Z C L O 722} /+$ border cell clusters showed impaired migration, even in the absence of Psid overexpression (Table 2). Moreover, $\operatorname{Tm} 1^{\mathrm{Su}(f l w) 4} /+$ border cell clusters expressing EGFP-actin exhibited abnormal protrusions that resembled those caused by overexpression of Psid and EGFPactin (Fig. 4D). Since reduction in tropomyosin concentration causes a similar phenotype as overexpression of Psid, tropomyosin and Psid may exert opposing effects on actin organization or dynamics.

We tested the simplest possibility, which was that Psid might interfere with Tm1 binding to F-actin. We first confirmed that Tm1 can cosediment with F-actin in an F-actin pelleting assay (Fig. 5G). The presence of purified Psid protein caused 3.5-fold less Tm1 to pellet with F-actin (Fig. 5H,I), providing a possible mechanistic explanation for the observed genetic interaction.

These findings suggested that a balance between Tm1 and Psid activities is important for proper protrusion dynamics and border cell migration. We predicted, therefore, that $\operatorname{Tm} 1$ mutants would exhibit migration defects. Tm1 mutations are homozygous lethal, so we examined mosaic egg chambers in which all border cells were homozygous mutant for Tm1 (Fig. 6A-F). As predicted, two different $T m 1$ alleles exhibited penetrant migration defects (Fig. 6J). Since Psid and Tm1 exhibit antagonistic effects in other assays, we tested whether reducing the genetic dosage of psid would have an impact on the Tm1 
A
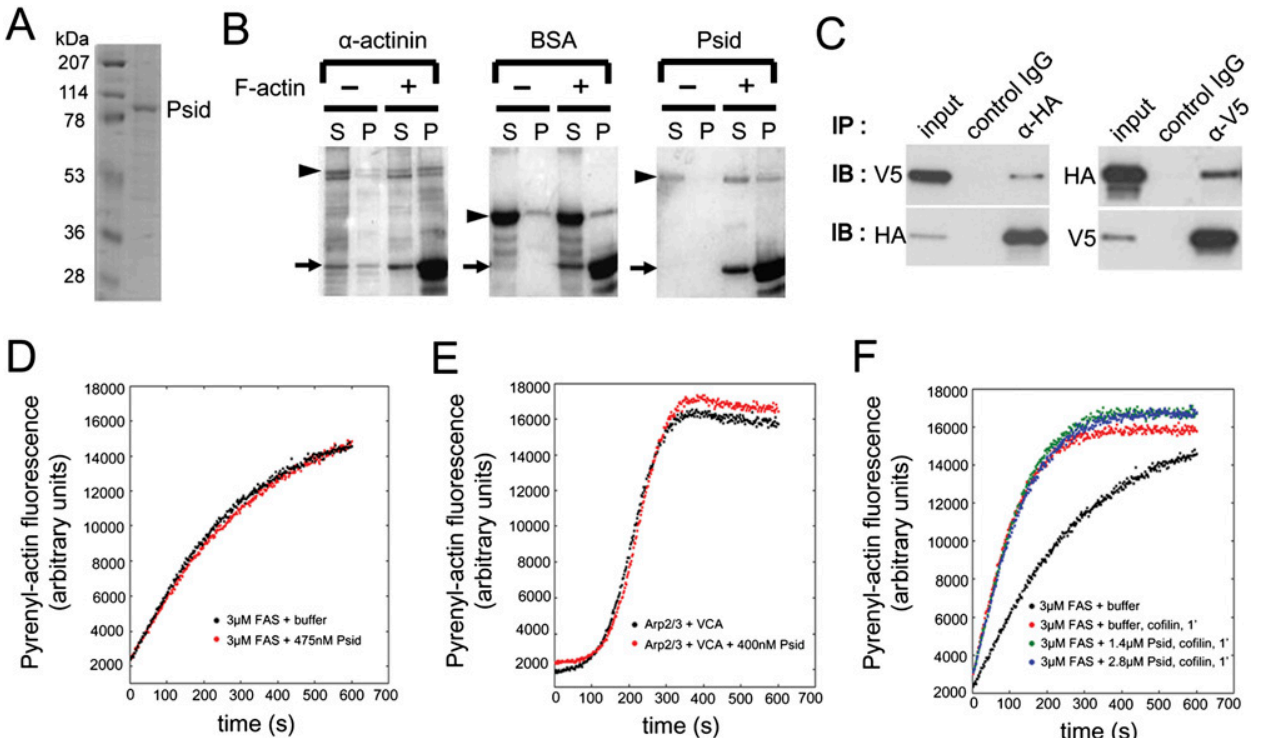

$\mathrm{E}$

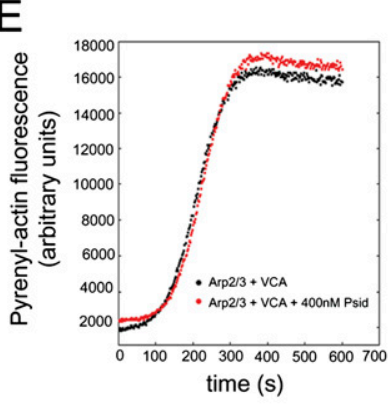

$\mathrm{F}$

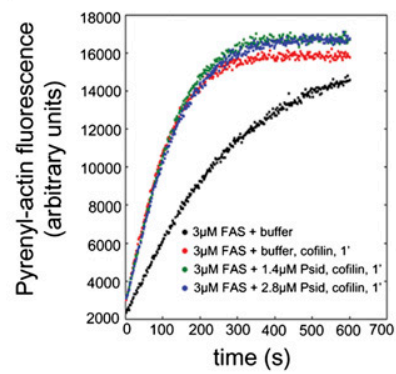

G

$\mathrm{H}$
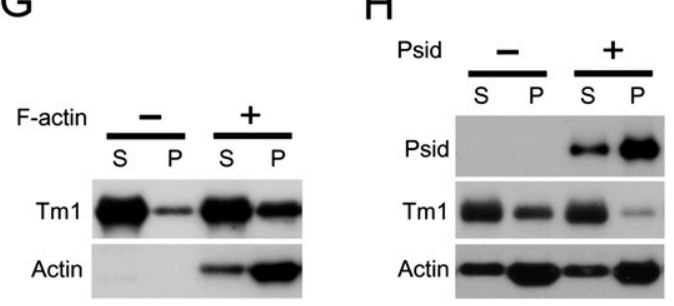

I

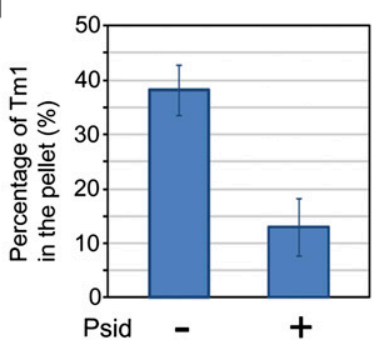

Figure 5. Biochemical analysis of purified Psid protein. (A) Coomassie Blue-stained SDS gel showing purified, recombinant His-tagged Psidin. A fraction from the peak of protein eluted from the Hi-TrapTM chelating HP column is shown. $(B)$ F-actin pelleting assay. The indicated proteins were incubated in the absence $(-)$ or presence $(+)$ of F-actin and then centrifuged at 150,000g. The supernatant (S) and pellet $(\mathrm{P})$ fractions were analyzed by PAGE and silver-stained. Psid protein is not detectable in the pellet in the absence of actin. In contrast, in the presence of F-actin, a significant signal is present in the pellet, similar to the positive control $\alpha$-actinin. There is no change in the amount of BSA, the negative control, found in the pellet in the presence versus absence of F-actin. Arrowheads indicate the bands corresponding to $\alpha$-actinin, BSA, and Psid. Arrows indicate actin. (C) Immunoblots (IB) of immunoprecipitated (IP) HA- and V5-tagged Psid proteins. Anti-HA and anti-V5 antibodies were used for immunoprecipitation and immunoblots, respectively. Changing antibodies for immunoprecipitation and immunoblots showed the same result. Lysate $(0.5 \%)$ used in the immunoprecipitation was loaded for the input. $(D)$ Psid does not affect the rate of actin polymerization from FAS. Seeded polymerization reactions contained $1 \mu \mathrm{M}$ G-actin $(5 \%$ pyrenelabeled) and $3 \mu \mathrm{M}$ FAS (20- $\mu \mathrm{L}$ aliquot), with or without $475 \mathrm{nM}$ psidin, as indicated, in $20 \mathrm{mM}$ imidazole $(\mathrm{pH} 7.0), 50 \mathrm{mM} \mathrm{KCl}, 2 \mathrm{mM}$ $\mathrm{MgCl}_{2}, 1 \mathrm{mM}$ EGTA, $0.2 \mathrm{mM}$ ATP, and $0.1 \mathrm{mM}$ DTT (MKEI-50 buffer). Fluorescence of pyrenyl-actin (excitation at $365 \mathrm{~nm}$, emission at $386 \mathrm{~nm}$ ) was monitored for $600 \mathrm{sec}$ at $25^{\circ} \mathrm{C}$. Psid was dialyzed in MKEI-50 prior to use. (E) Psid does not affect actin nucleation by Arp2/3 complex and the VCA domain of N-WASP. Actin polymerization reactions contained $24 \mathrm{nM}$ Arp2/3 complex, $0.75 \mathrm{nM}$ GST-VCA, and 1 $\mu \mathrm{M}$ G-actin, with and without $400 \mathrm{nM}$ psidin, as indicated, in MKEI-50 buffer. Fluorescence of pyrenyl-actin was monitored for 600 sec at $25^{\circ} \mathrm{C}$. (F) Psid does not affect actin filament severing by cofilin. Actin filament severing by cofilin was assessed in reactions containing 3 $\mu \mathrm{M}$ FAS $(20 \mu \mathrm{L})$ incubated with either MKEI-50 buffer or Psid, as indicated for $4 \mathrm{~min}$ at room temperature. Cofilin (325 $\mathrm{nM}$ final concentration) was added as indicated to the FAS-Psid mixture, and the reaction was incubated for an additional 1 min prior to dilution into $1 \mu \mathrm{M}$ G-actin (5\% pyrene-labeled) in MKEI-50. The fluorescence of pyrenyl-actin was monitored for $600 \mathrm{sec}$ at $25^{\circ} \mathrm{C}$. (G) F-actin pelleting assay for purified GST-fused Tm1 protein. $(H, I)$ Psid interferes with Tml binding to F-actin. A representative result of F-actin pelleting assay of Tm1 in the absence or presence of Psid protein is shown in $D$. The fraction of Tm1 in the pellet was quantified from Western blots such as that shown in $D$. The average of four different experiments is shown. Error bars indicate the standard deviations. In $D$ and $E$, each protein was visualized by Western blotting with anti-actin, anti-GST, and anti-Psid antibodies, respectively.

migration defects. Strikingly, border cells simultaneously homozygous mutant for $\operatorname{Tm} 1$ and psid exhibited less severe migration defects than either mutant alone (Fig. 6G-J).

When tropomyosin binds actin filaments, it modifies the ability of other proteins-such as cofilin, Arp2/3 complex, and myosin - to interact with actin. For example, tropomyosin binding interferes with cofilin-mediated severing of actin filaments (DesMarais et al. 2002). Cofilin is also required for border cell migration (Chen et al. 2001). Although null alleles of twinstar (tsr, the gene coding for cofilin) are lethal, $58 \%$ of adult flies that are heterozygous for two hypomorphic alleles, $t s r^{1}$ and $t s r^{\text {ntf }}$, survive at $18^{\circ} \mathrm{C}$ and exhibit border cell migration defects. To determine if $t s r$ and $p s i d$ interact genetically, we crossed $p$ sid mutations 
Table 2. Genetic interactions between Psid and actin regulatory proteins in border cell migration

\begin{tabular}{|c|c|c|}
\hline Genotype & Migration defect & $n$ \\
\hline UAS-psid; slbo-Gal4 & $2.8 \%$ & 69 \\
\hline UAS-psid; Tm1 $1^{Z C L 0722} /+$ & $9.7 \%$ & 165 \\
\hline UAS-psid; slbo-Gal4; Tm1 $1^{Z C L 0722} /+$ & $45.1 \%$ & 131 \\
\hline UAS-psid; Tm1 $1^{\text {Sulfflw)4 } /+}$ & $1.9 \%$ & 104 \\
\hline UAS-psid; slbo-Gal4; $\operatorname{Tm} 1^{\operatorname{Su}(f l w) 4} /+$ & $49.1 \%$ & 155 \\
\hline UAS-psid; Tm1 $1^{P Z 2299} /+$ & $11.5 \%$ & 61 \\
\hline UAS-psid; slbo-Gal4; Tm1 $1^{P Z 2299} /+$ & $26.7 \%$ & 120 \\
\hline UAS-psid; slbo-Gal4, +/tsr ${ }^{1}$ & $1.7 \%$ & 57 \\
\hline UAS-psid; slbo-Gal4; $\operatorname{ssh}^{1-63} /+$ & $3.9 \%$ & 103 \\
\hline UAS-psid; slbo-Gal4; wsp $/+$ & $5.1 \%$ & 137 \\
\hline UAS-psid; slbo-Gal4; kette ${ }^{I 4-48} /+$ & $1.8 \%$ & 113 \\
\hline UAS-psid; slbo-Gal4; $\operatorname{rac1}^{111}, \operatorname{rac}^{24} /+$ & $1.8 \%$ & 110 \\
\hline UAS-psid; slbo-Gal4, +/zip ${ }^{1 D 16}$ & $5.1 \%$ & 156 \\
\hline
\end{tabular}

Migration defect was determined by counting the number of stage 10 egg chambers showing the incomplete migration. (n) Total number of stage 10 egg chambers counted in the indicated genotype.

into the $t s r$ hypomorphic background. Strikingly, $t s r^{1} / t s r^{\text {ntf }}$ flies that were also heterozygous for psid were $100 \%$ lethal (Supplemental Table S1). This was true for three different psid alleles, making it unlikely that it was due to a nonspecific genetic background effect. Similarly $t s r^{1} / t s r^{n t f}$ was fully lethal in combination with a heterozygous mutation in the cofilin activator slingshot (ssh) (Supplemental Table S1). Thus, both biochemical and genetic interaction data support a role for Psid in modulating actin dynamics.

\section{Human Psid required for MCF10A cell migration}

To determine whether the function of Psid is conserved in mammalian cells, we examined the effect of silencing C12orf30, the human homolog of Psid, in MCF10A breast epithelial cells using siRNA. MCF10A cells are a good model to examine collective, directional cell migration in a wound healing assay (Simpson et al. 2008). After scratch/ wounding a confluent monolayer in EGF-treated cultures, control cells move as a sheet, where cells at the edge of the wound display significant protrusive activity and lead the coordinated directional movement to close the wound (Fig. 7A; Supplemental Movie S7). Time-lapse imaging demonstrated that C12orf30 knockdown dramatically affected the speed and persistence of migration, resulting in a significant suppression of wound closure (Fig. 7A,B; Supplemental Movie S8). Two distinct siRNA sequences showed similar phenotypic effects, confirming the specificity of the SMART pool (data not shown). C12orf30 overexpression, on the other hand, induced the opposite effect, causing a significant increase in both cell speed and persistence, which resulted in faster closure of the wound (Fig. 7C; Supplemental Movies S9, S10). The cells at the leading edge of the monolayer also displayed obviously larger protrusions than control cells.

To further characterize the enhanced protrusive activity in cells overexpressing C12orf30, we examined EGFinduced membrane protrusion dynamics (Supplemental Fig. S4A; Supplemental Movies S11, S12). Cells were starved for $4 \mathrm{~h}$ and acutely stimulated with EGF, and membrane protrusions were recorded by time-lapse microscopy. C12orf30 overexpression increased the extent of protrusion in response to EGF (Supplemental Fig. S4B); this was consistent with the increase in migration speed and the larger protrusions observed in the wound healing assay. These results show that Psid plays an important role in the regulation of EGF-induced membrane protrusion and migration of MCF10A cells.

\section{Discussion}

Border cell migration serves as a genetically tractable model system for the identification of genes controlling cell motility. Numerous genes have been identified in forward genetic screens for border cell migration mutants, and major insights into the signaling pathways that govern their specification, as well as the timing and direction of

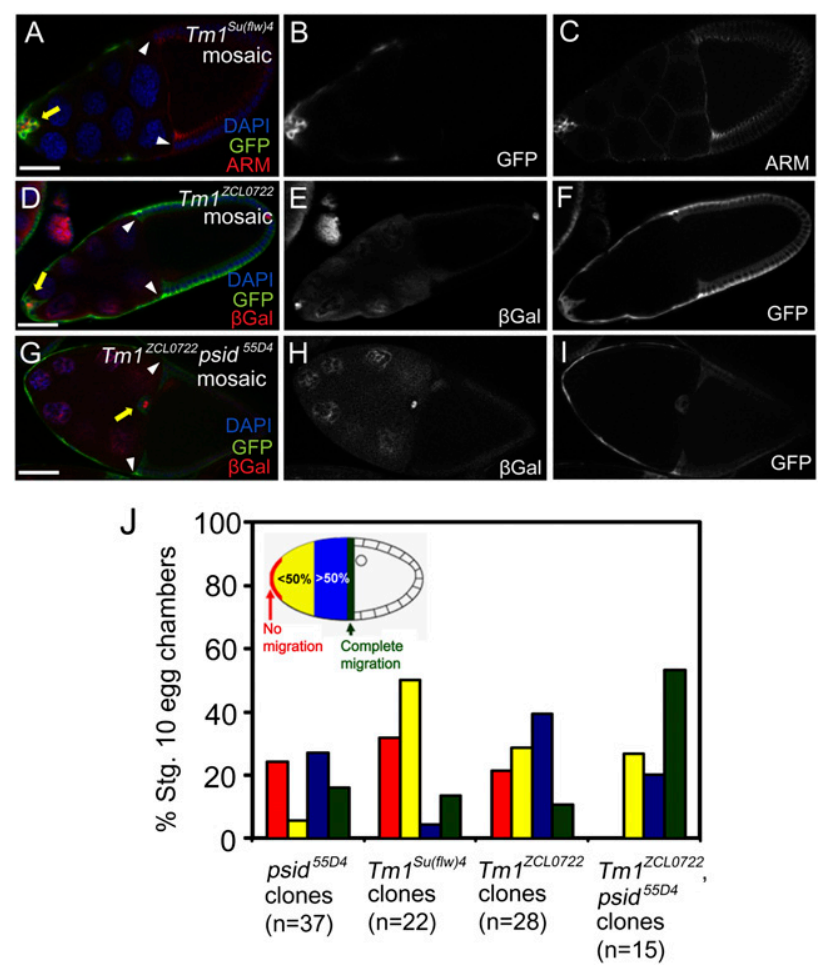

Figure 6. Border cell migration phenotypes by Tm1 mutations. $(A-C)$ Defective migration of $T m 1^{S u(f l w) 4}$ mutant clones. Homozygous mutant cells are labeled with GFP. $(D-F)$ Defective migration of $T m 1^{Z C L O 722}$ mutant clones. (E) Homozygous mutant cells are labeled with the absence of $\beta$-Galactosidase expression. (F) Since $\operatorname{Tm} 1^{Z C L O 722}$ is a GFP-Trap insertion, homo- or heterozygous mutant cells are GFP-positive. $(G-I)$ Normal migration of $T m 1^{Z C L 0722}, p^{2} d^{55 D 4}$ double-mutant border cell clones. Homozygous mutant cells are $\beta$ Gal-negative and GFP-positive. ( $J$ ) Histogram summarizing the migration defects. The indicated numbers $(n)$ mean numbers of egg chambers containing border cells mutant for the indicated mutations. Tm1 $1^{\text {ZCLO722 }}, p_{s i d}^{55 D 4}$ double mutants showed less severe migration defects compared with each single mutant. In $A, D$, and $G$, arrows indicate border cell clusters and arrowheads indicate the border between the oocyte and nurse cells. Bars, $50 \mu \mathrm{m}$. 
A

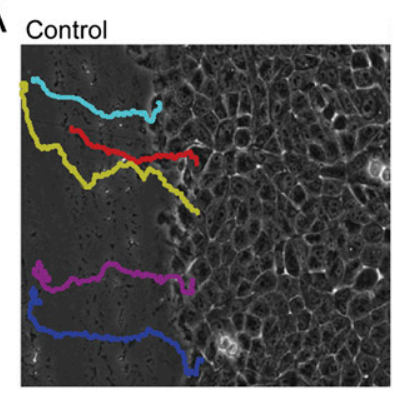

C12orf30 (SP siRNA)

B
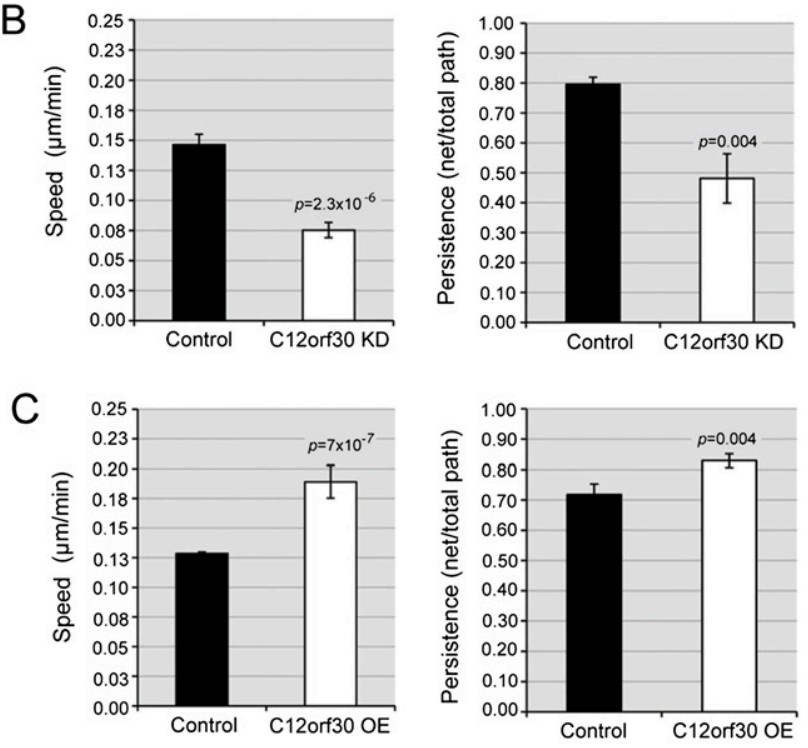

D

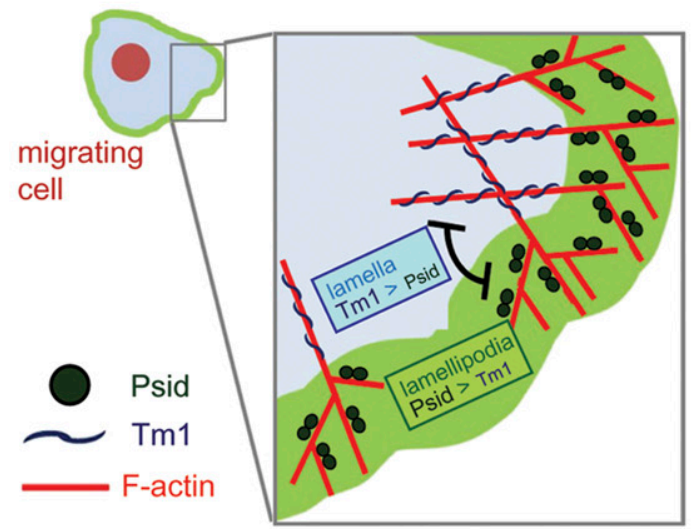

Figure 7. Effects of C12orf30 knockdown (KD) and overexpression (OE) on wound closure in MCF10A cells. (A) The paths of five individual cells from the wound edge were tracked for control and C12orf30 knockdown cells. $(B, C)$ Quantification of cell speed (microns per minute) and persistence of cells at the wound edge in control cells versus those transfected with the siRNA SMART pool $(B)$ or MCF10A cells infected with the pBabe-C12orf30 overexpression construct $(C)$. Values are means \pm SEM. $(D)$ Schematic representation of the complementary distributions and proposed antagonistic functions of Psidin and tropomyosin in a migrating cell. Psidin in the lamellipodium inhibits tropomyosin, promoting more dynamic assembly and disassembly. In contrast, tropomyosin is concentrated in the more stable lamellum, where it stabilizes actin filaments. border cell movement, have been described (for review, see Rørth 2002; Montell 2003). Two genome-wide expression profiles for migrating border cells have also been reported (Borghese et al. 2006; Wang et al. 2006). Although border cell migration has been extensively characterized, saturation for border cell migration mutants has not yet been reached. In particular, our understanding of the regulation of actin dynamics in migrating border cells is incomplete.

In the leading edge of migrating cells in culture, the turnover of actin filaments occurs rapidly and dynamically (Pollard and Borisy 2003). Actin filament growth by the addition of profilin-associated G-actin to barbed ends is the major force for membrane protrusion. Just behind the leading edge, actin filaments are severed and depolymerized by actin-disassembling factors such as cofilin. This process is also important for the continued rapid growth of filaments because dissociation of actin subunits replenishes the pool of monomeric actin required for further polymerization, and filament severing provides new barbed ends, which serve as substrates for rapid polymerization (DesMarais et al. 2005), particularly when the G-actin concentration is high. Further inside the cell, in the region known as the lamellum, longer and more stable actin filaments, together with myosin and tropomyosin, form a contractile network, which provides traction via focal adhesions that link the F-actin stress fibers to the substrate (Ponti et al. 2004; Gupton et al. 2005).

It is not clear to what extent cells migrating in a threedimensional environment share this precise organization of the actin cytoskeleton, and it is more difficult to probe cytoskeletal dynamics in molecular detail in vivo. However, protrusion dynamics are clearly important in vivo as well as in vitro. Migrating border cells, for example, extend and retract long protrusions enriched in actin filaments (Fulga and Rørth 2002; Prasad and Montell 2007) and require both cofilin and profilin to move normally (Verheyen and Cooley 1994; Chen et al. 2001). They move in response to chemotactic growth factors, which stimulate receptor tyrosine kinases that are highly related to mammalian chemoattractant receptors. Therefore, the mechanisms governing border cell migration are likely to share much in common with the movement of mammalian cells, and the genetic tractability of the system offers the possibility of identifying new molecules. Multiple lines of evidence presented here-including loss-of-function and gain-offunction experiments, live imaging, and protein interactions-demonstrate that the conserved protein Psid binds F-actin, modulates cellular protrusion/retraction dynamics, and promotes migration not only in border cells, but also in mammalian cells.

\section{psid phenotypes suggest a function in actin dynamics}

In each cell type studied, the loss-of-function and gain-offunction $p$ sid phenotypes suggested altered actin dynamics. In border cells and MCF10A cells, loss of psid caused impaired migration. In S2 cells and MCF10A cells, altered protrusion dynamics were evident upon Psid depletion. In mutant nurse cells, F-actin levels were elevated and cortical actin was irregular and disorganized, whereas 
nurse cells overexpressing Psid showed a reduction in phalloidin staining. These findings suggest more specifically that Psid normally has a negative effect on filament stability, at least in this cell type.

The Psid overexpression phenotype in border cells also suggests defective actin dynamics. In EGFP-actin-expressing cells, Psid overexpression caused protrusions to grow exceptionally long and thin and to fail to retract. This phenotype is very different from that caused by overexpression of Enabled, which promotes addition of actin monomers to free barbed ends. When Enabled is overexpressed in border cells together with EGFP-actin, numerous short, fine protrusions form all over the cluster (Gates et al. 2009). The Psid overexpression phenotype did, however, resemble that reported previously for border cells mutant for spaghetti squash, a Drosophila homolog of nonmuscle myosin II light chain, which also show extremely long protrusions (Fulga and Rørth 2002). We observed a similar effect in tropomyosin heterozygotes. It is easy to imagine that, in the absence of adequate tropomyosin or myosin, actin filaments behind the leading edge are less stable and contractility is reduced, thus impeding retraction of protrusions and forward translocation of the cell body. Thus, Psid overexpression resembles inadequate activity of myosin and tropomyosin. The phenotype of cells overexpressing the human homolog of Psid also resembled that of cells with reduced myosin II (Vicente-Manzanares et al. 2007) or myosin light chain kinase (Simpson et al. 2008).

Another contributing factor to the Psid overexpression phenotype could be cofilin, since psid and tsr also interact genetically. Cofilin severs actin filaments, which can provide new barbed ends and, somewhat counterintuitively, stimulate actin polymerization, particularly when the G-actin concentration is high. This effect may contribute to the generation of long protrusions when Psid is overexpressed and could explain why this effect is dramatic only when GFP-actin is also overexpressed. We did not detect a direct stimulation of cofilin's effect on actin in vitro however, suggesting that it is more likely the Psid-mediated antagonism of Tm that enhances cofilin, rather than a direct effect.

The activities of purified Psid protein in vitro provide a plausible mechanism for the observed effects in vivo (Fig. 7D). Psid has at least three biochemical activities: selfassociation, F-actin binding, and antagonizing Tm1 association with F-actin. These activities suggest that Psid forms dimers or higher-order multimers, which bind actin filaments. In contrast with Tm-decorated filaments, Psiddecorated filaments remain permissive for Arp $2 / 3$ complex-mediated actin filament nucleation and severing by cofilin. The observations in S2 cells that Psid knockdown resembles the cofilin knockdown phenotype and that Psid overexpression resembles that of tropomyosin knockdown (Iwasa and Mullins 2007) are consistent with a model in which Psid antagonizes the action of tropomyosin. However, this may not be the only function of Psid.

The protein most related to Psid in Saccharomyces cerevisiae is Mdm20, which associates with NatB, an $\mathrm{N}$-acetyltransferase enzyme. The precise function of the $\mathrm{Mdm} 20$ subunit is unknown. In budding yeast, NatB acetylates tropomyosin and actin, strengthening their interaction (Polevoda et al. 2003; Singer and Shaw 2003). Interestingly, mdm20 mutants lack the normal actin cables that run from mother cell to bud, a phenotype that can be suppressed by specific mutations in actin or tropomyosin.

Like the work in yeast, the observed genetic interactions in Drosophila also implicate Psid in actin dynamics. However, it is difficult to compare the results directly, since the genetic interactions were carried out differently. In yeast, specific amino acid substitutions in tropomyosin and in actin were found in a genome-wide screen for suppressors of loss-of-function mutations in mdm20. We were not able to do the same experiment, since we do not have the same tropomyosin or actin alleles in flies. The genetic interaction in Drosophila showed that partial loss of function of tropomyosin enhanced the effect of Psid overexpression, and that reduction in psid gene dosage partially suppressed the migration defects of Tm1 mutant border cells.

It remains to be seen whether the yeast protein can interact directly with F-actin or whether Psid functions as part of an $\mathrm{N}$-acetyltransferase complex. Since the sequence identity between the yeast and Drosophila proteins is low (13\% identical; $31 \%$ similar), there may also be some differences in their functions. Alternatively, these proteins may be multifunctional. If Psid does function as part of an $\mathrm{N}$-acetyltransferase complex, its ability to bind F-actin could, in principle, help localize the enzyme complex to actin filaments in proximity to key substrates such as actin and tropomyosin. The Drosophila gene CG14222 encodes a protein that is likely to be the homolog of the catalytic subunit of the yeast $\mathrm{N}$-acetyltransferase complex; however, no mutant alleles are available.

Drosophila psid was shown previously to be required for clearance of bacterial infections (Brennan et al. 2007). Mutant phagocytes lacking Psid were able to engulf bacteria but not degrade them. This may reflect a requirement for normal actin dynamics and cytoskeletal organization for the movements and/or functions of intracellular phagosomes, or, alternatively, that Psid plays multiple roles inside cells.

\section{Conservation of function in mammalian cells}

One reason to carry out genetic screens in Drosophila is to identify genes and proteins with conserved functions in mammals that have not been identified using other approaches. Therefore, it is of interest that C12orf30, the human homolog of Psid, exhibited loss-of-function and gain-of-function phenotypes related to cell migration speed and persistence as well as protrusion dynamics in MCF10A mammary epithelial cells. Live-imaging studies reveal that $\mathrm{C} 12$ orf30 knockdown cells fail to migrate directionally into a scratch wound, even though they exhibit some mobility within the monolayer. Moreover, membrane ruffling at the leading edge was greatly reduced in the knockdown cells, which correlates well with the knockdown phenotype in S2 cells. Conversely, overexpression of C12orf30 caused increased protrusion and delayed retraction relative to control MCF10A cells 
following EGF stimulation. Together, these studies suggest a conserved role for Psid and C12orf30 in protrusion/ retraction dynamics and cell migration, and that all of the proteins that regulate actin dynamics and cell migration have not yet been identified.

\section{Materials and methods}

\section{Drosophila genetics}

Drosophila culture and crosses were performed following standard procedures at $25^{\circ} \mathrm{C}$, except where indicated. To map the psid locus, the original psid ${ }^{85 D 1}$ line was crossed to the deficiency kit for 3R (Bloomington Stock Center) and scored for lethality. psid $d^{85 D 1}$ and psid ${ }^{554}$ alleles were meiotically mapped following the border cell migration phenotype with respect to the recessive markers curved (86D1-4), stripe (90D2-7), and claret (99B8-10). The piggybac line PBac[e02846] failed to complement $p s i d^{85 D 1}$ and psid $^{5504}$ alleles.

To negatively mark mosaic clones in egg chambers, FRT $^{82 \mathrm{~B}}$, psid/TM3 flies were crossed to hsp70-FLP; FRT $^{82 \mathrm{~B}}$, ubGFP ${ }^{\text {nls }}$ or hsp70-FLP; FRT ${ }^{82 \mathrm{~B}}$, arm-lacZ. To positively mark mosaic clones in border cell clusters, c306-Gal4; FRT ${ }^{82 \mathrm{~B}}$, psid/TM3 flies were crossed to hsp70-FLP, UAS-mCD8GFP; FRT ${ }^{82 \mathrm{~B}}$, tub-Gal80. c306Gal4; FRT $^{82 \mathrm{~B}}$ line was used as a control. Dissection of ovaries was performed 7 or $8 \mathrm{~d}$ after heat shock. Tm1 mutant mosaic clones were generated in the same way using FRT ${ }^{82 \mathrm{~B}}, \mathrm{Tm} 1 / \mathrm{TM} 3$ flies.

To overexpress Psid in the egg chamber, the Gal4/UAS system was used (Brand and Perrimon 1993). The following Gal4 drivers were used: slbo-Gal4 for border cell expression, triple-Gal4 for germline expression, and actin-Gal4 for ubiquitous expression. Flies with the designated genotypes were incubated overnight at $29^{\circ} \mathrm{C}$ or $32^{\circ} \mathrm{C}$ before the dissection of ovaries. For the rescue of lethality caused by psid mutations, UAS-psid was expressed by actin-Gal4 in $p s i d^{55 D 4} / p s i d^{85 D 1}$ flies.

\section{Immunohistochemistry and immunofluorescence}

Ovary dissection was performed in Schneider's medium (GIBCO) supplemented with $10 \%$ FBS (Sigma). Ovary fixation and staining with antibodies, phalloidin, and DAPI was performed as described previously (Bai et al. 2000). The primary antibodies used were mouse anti-Singed (1:50; SN 7C), mouse anti-Armadillo (1:100; N2 7A1, Developmental Studies Hybridoma Bank), mouse or rabbit anti-GFP (1:2000; Molecular Probes), mouse anti-HA (1:1000; Santa Cruz Biotechnology), and rabbit anti-Psid (1:1000). Alexa Fluor-conjugated goat anti-mouse or anti-rabbit IgG antibodies were used as the secondary antibodies (Molecular Probes). In situ hybridization was performed with sense or antisense probes against psid mRNA as described previously (Wang et al. 2006).

For S2 cell immunostaining, cells were plated on coverslips coated with $0.5 \mathrm{mg} / \mathrm{mL}$ Concanavalin-A (Sigma) for $1 \mathrm{~h}$ and fixed with $4 \%$ formaldehyde for $10 \mathrm{~min}$. After washing three times in PBT $(0.1 \%$ Triton X-100), primary and secondary antibodies were incubated for $1 \mathrm{~h}$ in PBT. Phalloidin and DAPI were incubated with secondary antibodies.

\section{Generation of a polyclonal antibody and expression constructs}

A peptide corresponding to the amino acid sequence 799-812 of Psid protein (ESNGIDGLWKRRGQ) was used as an antigen for the polyclonal antibody production in rabbits (Genescript).

To make a Psid expression construct for generating transgenic fly lines, a full-length cDNA of the psid gene from EST clone
AT25164 was subcloned into pUAST vector or pUASp vector (Rørth 1998). For germline transformation, each construct was injected in a w1118 embryo according to standard procedures (Bestgene).

For Psid expression in S2 cells, a full-length psid cDNA was amplified by PCR, with EST clone AT25164 as a template, and subcloned in-frame into pMT/V5-HisB (Invitrogen), pUAST-HA, or pUAST-mRFP vector.

To make Tm1 constructs for expression in S2 cells or bacteria, a full-length cDNA of an isoform of the Tm1 gene was amplified by PCR from EST clone LD11194 and subcloned in-frame into pUAST-mRFP or pGEX-5X-3 vector.

\section{S2 cell culture and RNAi}

S2 cells were cultured in Schneider's medium (GIBCO) supplemented with 10\% FBS (Sigma). Transfection was performed using Effectene (Qiagen). To generate a stable line to express the Psid protein, pMT/V5-HisB containing full-length psid cDNA was cotransfected with pBS-Puro. Stable line selection and maintenance was performed as described previously (Benting et al. 2000).

In order to knock down Psid expression in S2 cells, RNAi experiments with long dsRNA were performed (Rogers and Rogers 2008). To generate templates for in vitro transcription, two different regions of $p s i d$ cDNA were amplified by PCR and cloned into pGEM-T ${ }^{\text {easy }}$ vector (Promega). Sense and antisense RNAs were transcribed with T7 RNA polymerase (Ambion) and then hybridized overnight. S2 cells were cultured in SF 900 medium (GIBCO) containing $10 \mu \mathrm{g} / \mathrm{mL}$ dsRNA, which was exchanged every $24 \mathrm{~h}$. Cells were harvested after day 6 and analyzed by Western blot and live imaging.

\section{Live imaging of border cells and S2 cells}

Live-imaging experiments of border cell migration were performed as described previously (Prasad et al. 2007). Briefly, ovaries were dissected in Schneider's medium (GIBCO) supplemented with $10 \%$ FBS (Sigma), $0.6 \times$ penicillin/streptomycin (GIBCO), and $0.2 \mathrm{mg} / \mathrm{mL}$ insulin (Sigma). Egg chambers were mounted on a 50-mm Petriperm plate (Greiner Bio) and covered with a $22-\mathrm{mm}$ coverslip (Fisher).

For live-imaging experiments of S2 cell membrane dynamics, a S2 cell line expressing EGFP-fused actin was used (Rogers et al. 2003). EGFP-actin was expressed with $1 \mathrm{mM} \mathrm{CuSO}_{4}$ induction for 3-6 h, then S2 cells were plated on coverslips coated with 0.5 $\mathrm{mg} / \mathrm{mL}$ Concanavalin-A for $1 \mathrm{~h}$. Coverslips were mounted on a 50-mm Petriperm plate for imaging.

Time-lapse images were taken using an Axiovision MRm camera on a Zeis Axioplan 2 microscope at room temperature. $Z$-stack images were integrated into a maximal intensity projection (MIP) image to generate final images.

S2 cell kymographs were generated from time-lapse sequences (one frame/10 sec over $10 \mathrm{~min}$ ) of S2 cells expressing GFP-actin along 1-pixel-wide lines oriented perpendicular to the cell periphery and spaced in a radial pattern around each cell (12-17 kymographs were generated per cell; five to seven cells were analyzed for each condition). Each protrusion and retraction was marked with a straight line along its leading or trailing edge, respectively. Slopes of these lines were used to calculate the velocities of protrusion and retraction, and projections of the lines along the $X$-axis (time) or $Y$-axis (distance) were used to calculate the persistence and distance, respectively, of protrusions (Hinz et al. 1999). Similarly, the trajectories of GFP-actin-enriched structures within the lamellipod were tracked to measure rates of retrograde flow of F-actin. 
The width of the lamellipodium was measured from summed $Z$-projections of the time-lapse sequences wherein the most dynamic region appears as a bright band encircling the cell at its periphery. The width of the bright band was measured at $\sim 20$ locations per cell in a radial pattern around each cell; a minimum of four cells was measured for each condition.

\section{Psid coimmunoprecipitation and protein purification}

For coimmunoprecipitation, HA- or V5-tagged Psid proteins were expressed in S2 cells. Cells were harvested, washed in cold PBS once, and lysed in the lysis buffer $(20 \mathrm{mM}$ Tris at $\mathrm{pH} 8.0,150$ $\mathrm{mM} \mathrm{NaCl}, 1 \mathrm{mM}$ EDTA, 10\% glycerol, 1\% NP40, 1:500 protease inhibitor cocktail [Sigma]). Mouse anti-HA antibody and mouse anti-V5 antibody were used for immunoprecipitation and immunoblotting.

To purify recombinant Psid protein from a S2 stable line, a 200$\mathrm{mL}$ culture containing $5 \times 10^{6}$ cells per milliliter was induced overnight with $1 \mathrm{mM} \mathrm{CuSO}_{4}$. Cells were harvested and washed in PBS once. Cells were lysed in the binding buffer $(5 \mathrm{mM}$ imidazole, $20 \mathrm{mM}$ Tris- $\mathrm{HCl}$ at $\mathrm{pH} 8.0,0.2 \%$ Triton X-100, $150 \mathrm{mM} \mathrm{KCl}, 5 \%$ glycerol, $5 \mathrm{mM}$ 2-mercaptoethanol, 1:500 protease inhibitor cocktail [Sigma], $1 \mathrm{mM}$ PMSF) for $1 \mathrm{~h}$ at $4^{\circ} \mathrm{C}$. Cell lysate was cleared by centrifugation. The supernatant was flowed through Hi-TrapTM Chelating HP column (GE Healthcare) charged with $\mathrm{NiCl}_{2}$, and Psid protein was eluted with imidazole.

To purify GST-fused Tm1 protein from bacteria, protein expression was induced with $0.8 \mathrm{mM}$ IPTG overnight at room temperature. Cells were harvested and lysed by sonication in the GST-binding buffer $(25 \mathrm{mM}$ Tris at $\mathrm{pH} 7.5,150 \mathrm{mM} \mathrm{KCl}, 1 \mathrm{mM}$ EDTA, 1:500 protease inhibitor cocktail). After centrifugation, the supernatant was collected and incubated with pre-equilibrated glutathione-agarose resin overnight at $4^{\circ} \mathrm{C}$. Tm1 protein was eluted with $10 \mathrm{mM}$ glutathione in GST-binding buffer.

\section{In vitro actin biochemical assays}

F-actin cosedimentation was performed according to the manufacturer's protocol (Cytoskeleton). Briefly, $2 \mu \mathrm{M}$ purified Psid, 0.5 $\mu \mathrm{M}$ purified $\mathrm{Tm} 1$, or $2 \mu \mathrm{M}$ control proteins $(\alpha$-actinin for a positive control and BSA for a negative control) were incubated with 4 or 18 $\mu \mathrm{M}$ F-actin prepared freshly for $1 \mathrm{~h}$ in $\mathrm{F}$ buffer $(5 \mathrm{mM}$ Tris- $\mathrm{HCl}$ at pH 8. 0, 0. $2 \mathrm{mM} \mathrm{CaCl}_{2}, 50 \mathrm{mM} \mathrm{KCl}, 2 \mathrm{mM} \mathrm{MgCl}_{2}, 1 \mathrm{mM} \mathrm{ATP)}$. For Psid inhibition on Tm1 binding to F-actin, 0.05-1 $\mu \mathrm{M}$ Psid and $0.5 \mu \mathrm{M} \mathrm{Tm} 1$ were coincubated with $4 \mu \mathrm{M}$ F-actin for $1 \mathrm{~h}$ in F buffer. Samples were centrifuged at 150,000 $\mathrm{g}$ for $1 \mathrm{~h}$ in a Beckman Airfuge (Beckman-Coulter), and supernatants and pellets were analyzed by SDS-PAGE and silver staining or Western blotting. Actin polymerization assays using pyrenyl-actin were performed in MKEI-50 buffer (20 mM imidazole, $1 \mathrm{mM}$ EGTA, $2 \mathrm{mM} \mathrm{MgCl}$, $1 \mathrm{mM} \mathrm{DTT}, 50 \mathrm{mM} \mathrm{KCl})$ with $3 \mu \mathrm{M}$ FAS $(20-\mu \mathrm{L}$ aliquot $)$ and $1 \mu \mathrm{M}$ G-actin (5\% pyrene-labeled), with or without Psid, in a final volume of $200 \mu \mathrm{L}$. Reactions to monitor actin nucleation by Arp2/3 complex contained $24 \mathrm{nM}$ Arp2/3 complex and $0.75 \mathrm{nM}$ GST-VCA, with and without added Psid. To assess actin filament severing by cofilin, a $20-\mu \mathrm{L}$ aliquot of $3 \mu \mathrm{M}$ FAS was incubated with Psid or buffer for $4 \mathrm{~min}$ at room temperature, prior to addition of $325 \mathrm{nM}$ cofilin for $1 \mathrm{~min}$; the reaction was subsequently diluted into $1 \mu \mathrm{M} \mathrm{G}$-actin (5\% pyrene-labeled) to monitor the rate of actin assembly from the FAS. Severing of filaments in the FAS results in increased rates of actin assembly compared with FAS not incubated with cofilin. For all assays, fluorescence of pyrenyl-actin (excitation at $365 \mathrm{~nm}$, emission at $386 \mathrm{~nm}$ ) was monitored for 600 $\mathrm{sec}$ at room temperature. Actin was purified from rabbit muscle and gel-filtered on a Sephacryl S-200 HR column (GE Healthcare) (Spudich and Watt 1971). Pyrene-labeled actin was prepared as described (Bryan 1986). Arp2/3 complex was purified from bovine calf thymus (Higgs et al. 1999).

\section{Mammalian cell culture, siRNA transfection, and virus infection}

MCF-10A cells were cultured as described (http://brugge.med. harvard.edu/protocols). Cells were transfected at $30 \%$ confluence, $16 \mathrm{~h}$ after plating in six- or 24-well dishes using Dharmacon reagents targeting C12orf30 (SMARTpool, catalog no. M-014530-00; individual siRNAs, catalog nos. D-014530-01 and D-014530-03). siRNAs were transfected at $50 \mathrm{nM}$ final concentration with DharmaFECT3 lipid, as recommended by the supplier (Thermo Fisher Scientific).

pBabe-C12orf30 or control pBabe constructs were transfected into 293T cells in the presence of virus package plasmid. Virus was collected after $24 \mathrm{~h}$ of transfection. MCF10A cells were infected with virus suspension and cultured in selection medium for $2 \mathrm{wk}$ with neomycin.

\section{Wound healing and area change studies}

For time-lapse video microscopy, C12orf30 knockdown cells, at $48 \mathrm{~h}$ post-transfection, and C12orf30 overexpression cells were wounded using a p200 pipette tip and imaged at 5-min intervals for $20 \mathrm{~h}$ using a $20 \times$ ELWD objective on a Nikon TE2000E automated inverted microscope at $37^{\circ} \mathrm{C}$. Imaging began $\sim 45 \mathrm{~min}$ post-wounding.

To investigate cell area change, cells were transfected in six-well dishes for $24 \mathrm{~h}$, then trypsinized and replated onto glass coverslips for a further $24 \mathrm{~h}$. Cells were starved (complete starvation) for $4 \mathrm{~h}$ in HBSS medium containing $10 \mathrm{mM}$ HEPES and $0.3 \%$ BSA. Individual cells were imaged at 10 -sec intervals for a total of 20 min, with EGF stimulation at 2 min after imaging (final concentration of $25 \mathrm{ng} / \mathrm{mL}$ ). Cells were imaged using a $20 \times$ DIC $0.75 \mathrm{NA}$ objective on a Nikon TE2000E inverted microscope. Area changes of individual cells were traced every minute by ImageJ, and all values are normalized over the corresponding areas at time 0 .

\section{Acknowledgments}

We thank Chang-Hun Lee for his technical support for biochemical experiments. This work was supported by R01 GM73164 (to D.J.M.), the Cell Migration Consortium U54-GM064346 (to J.S.B.), and R01 GM67222 (to D.A.S.).

\section{References}

Adrianantoandro E, Pollard TD. 2006. Mechanism of actin filament turnover by severing and nucleation at different concentrations of ADF/cofilin. Mol Cell 24: 13-23.

Bai J, Uehara Y, Montell DJ. 2000. Regulation of invasive cell behavior by Taiman, a Drosophila protein related to AIB1, a steroid receptor coactivator amplified in breast cancer. Cell 103: $1047-1058$.

Baum B, Perrimon N. 2001. Spatial control of the actin cytoskeleton in Drosophila epithelial cells. Nat Cell Biol 3: 883-890.

Benting J, Lecat S, Zacchetti D, Simons K. 2000. Protein expression in Drosophila Schneider cells. Anal Biochem 278: 59-68.

Blatch GL, Lassle M. 1999. The tetratricopeptide repeat: a structural motif mediating protein-protein interactions. Bioessays 21: 932-939.

Borghese L, Fletcher G, Mathieu J, Atzberger A, Eades WC, Cagan RL, Rørth P. 2006. Systematic analysis of the transcriptional switch inducing migration of border cells. Dev Cell 10: 497-508.

Brand AH, Perrimon N. 1993. Targeted gene expression as a means of altering cell fates and generating dominant phenotypes. Development 118: 401-415. 
Brennan CA, Delaney JR, Schneider DS, Anderson KV. 2007. Psidin is required in Drosophila blood cells for both phagocytic degradation and immune activation of the fat body. Curr Biol 17: 67-72.

Bryan J. 1986. Isolation of fascin, an actin-bundling protein, and SU45, an actin-severing/capping protein from sea urchin eggs. Methods Enzymol 134: 13-23.

Chen J, Godt D, Gunsalus K, Kiss I, Goldberg M, Laski FA. 2001. Cofilin/ADF is required for cell motility during Drosophila ovary development and oogenesis. Nat Cell Biol 3: 204-209.

Chhabra ES, Higgs HN. 2007. The many faces of actin: matching assembly factors with cellular structures. Nat Cell Biol 9: $1110-1121$.

Cooper JA, Schafer DA. 2000. Control of actin assembly and disassembly at filament ends. Curr Opin Cell Biol 12: 97-103.

D'Andrea LD, Regan L. 2003. TPR proteins: the versatile helix. Trends Biochem Sci 28: 655-662.

DesMarais V, Ichetovkin I, Condeelis J, Hitchcock-DeGregori SE. 2002. Spatial regulation of actin dynamics: a tropomyosinfree, actin-rich compartment at the leading edge. I Cell Sci 115: 4649-4660.

DesMarais V, Macaluso F, Condeelis J, Bailly M. 2005. Synergistic interaction between the Arp2/3 complex and cofilin drives stimulated lamellipod extension. J Cell Sci 117: 3499-3510.

Fulga TA, Rørth P. 2002. Invasive cell migration is initiated by guided growth of long cellular extensions. Nat Cell Biol 4: 715-719.

Gates J, Nowotarski SH, Yin H, Mahaffey JP, Bridges T, Herrera C, Homem CC, Janody F, Montell DJ, Peifer M. 2009. Enabled and Capping protein play important roles in shaping cell behavior during Drosophila oogenesis. Dev Biol 333: 90-107.

Geisbrecht ER, Montell DJ. 2004. A role for Drosophila IAP1mediated caspase inhibition in Rac-dependent cell migration. Cell 118: 111-125.

Goode S, Perrimon N. 1997. Inhibition of patterned cell shape change and cell invasion by Discs large during Drosophila oogenesis. Genes Dev 11: 2532-2544.

Gupton SL, Anderson KL, Kole TP, Fischer RS, Ponti A, HitchcockDeGregori SE, Danuser G, Fowler VM, Wirtz D, Hanein D, et al. 2005. Cell migration without a lamellipodium: translation of actin dynamics into cell movement mediated by tropomyosin. J Cell Biol 168: 619-631.

Higgs HN, Blanchoin L, Pollard TD. 1999. Influence of the C terminus of Wiskott-Aldrich syndrome protein WASp and the Arp2/3 complex on actin polymerization. Biochemistry 38: $15212-15222$.

Hinz B, Alt W, Johnen C, Herzog V, Kaiser HW. 1999. Quantifying lamella dynamics of cultured cells by SACED, a new computer-assisted motion analysis. Exp Cell Res 251: 234-243.

Ichetovkin I, Grant W, Condeelis J. 2002. Cofilin produces newly polymerized actin filaments that are preferred for dendritic nucleation by the Arp2/3 complex. Curr Biol 12: 79-84.

Iwasa JH, Mullins RD. 2007. Spatial and temporal relationships between actin-filament nucleation, capping, and disassembly. Curr Biol 17: 395-406.

Montell DJ. 2003. Border-cell migration: the race is on. Nat Rev Mol Cell Biol 4: 13-24.

Murphy AM, Montell DJ. 1996. Cell type-specific roles for Cdc42, Rac, and RhoL in Drosophila oogenesis. J Cell Biol 133: 617630.

Naora H, Montell DJ. 2005. Ovarian cancer metastasis: integrating insights from disparate model organisms. Nat Rev Cancer 5: 355-366.

Ono S. 2007. Mechanism of depolymerization and severing of actin filaments and its significance in cytoskeletal dynamics. Int Rev Cytol 258: 1-82.
Polevoda B, Cardillo T, Doyle TC, Bedi GS, Sherman F. 2003. Nat3p and Mdm20p are required for function of yeast NatB $\mathrm{N} \alpha$-terminal acetyltransferase and of actin and tropomyosin. J Biol Chem 278: 30686-30697.

Pollard TD, Borisy GG. 2003. Cellular motility driven by assembly and disassembly of actin filaments. Cell 112: 453-465.

Ponti A, Machacek M, Gupton SL, Waterman-Storer CM, Danuser G. 2004. Two distinct actin networks drive the protrusion of migrating cells. Science 305: 1782-1786.

Prasad M, Montell DJ. 2007. Cellular and molecular mechanisms of border cell migration analyzed using time-lapsed live-cell imaging. Dev Cell 12: 997-1005.

Prasad M, Jang AC, Starz-Gaiano M, Melani M, Montell DJ. 2007. A protocol for culturing Drosophila melanogaster stage 9 egg chambers for live imaging. Nat Protoc 2: 2467-2473.

Ridley AJ, Schwarts MA, Burridge K, Firtel RA, Ginsberg MH, Borisy G, Parsons JT, Horwitz AR. 2003. Cell migration: integrating signals from front to back. Science 302: 1704-1709.

Rogers SL, Rogers GC. 2008. Culture of Drosophila S2 cells and their use for RNAi-mediated loss-of-function studies and immunofluorescence microscopy. Nat Protoc 3: 606-611.

Rogers SL, Wiedemann U, Stuuman N, Vale RD. 2003. Molecular requirements for actin-based lamella formation in Drosophila S2 cells. I Cell Biol 162: 1079-1088.

Rørth P. 1998. Gal4 in the Drosophila female germline. Mech Dev 78: 113-118.

Rørth P. 2002. Initiating and guiding migration: lessons from border cells. Trends Cell Biol 12: 325-331.

Silver DL, Montell DJ. 2001. Paracrine signaling through the JAK/STAT pathway activates invasive behavior of ovarian epithelial cells in Drosophila. Cell 107: 831-841.

Simpson KJ, Selfors LM, Bui J, Reynolds A, Leake D, Khvorova A, Brugge JS. 2008. Identification of genes that regulate epithelial cell migration using an siRNA screening approach. Nat Cell Biol 10: 1027-1038.

Singer JM, Shaw JM. 2003. Mdm20 protein functions with Nat3 protein to acetylate Tpm 1 protein and regulate tropomyosinactin interactions in budding yeast. Proc Natl Acad Sci 100: 7644-7649.

Smolikov S, Schild-Prüfert K, Colaiácovo MP. 2008. CRA-1 uncovers a double-strand break-dependent pathway promoting the assembly of central region proteins on chromosome axes during C. elegans meiosis. PLoS Genet 4: e1000088. doi: 10.1371/journal.pgen.1000088.

Spudich JA, Watt S. 1971. The regulation of rabbit skeletal muscle contraction. I. Biochemical studies of the interaction of the tropomyosin-troponin complex with actin and the proteolytic fragments of myosin. J Biol Chem 246: 4866-4871.

Verheyen EM, Cooley L. 1994. Profilin mutations disrupt multiple actin-dependent processes during Drosophila development. Development 120: 717-728.

Vicente-Manzanares M, Zareno J, Whitmore L, Choi CK, Horwitz AF. 2007. Regulation of protrusion, adhesion dynamics, and polarity by myosins IIA and IIB in migrating cells. J Cell Biol 176: $573-580$.

Wang X, Bo J, Bridges T, Dugan KD, Pan TC, Chodosh LA, Montell DJ. 2006. Analysis of cell migration using wholegenome expression profiling of migratory cells in the Drosophila ovary. Dev Cell 10: 483-495. 


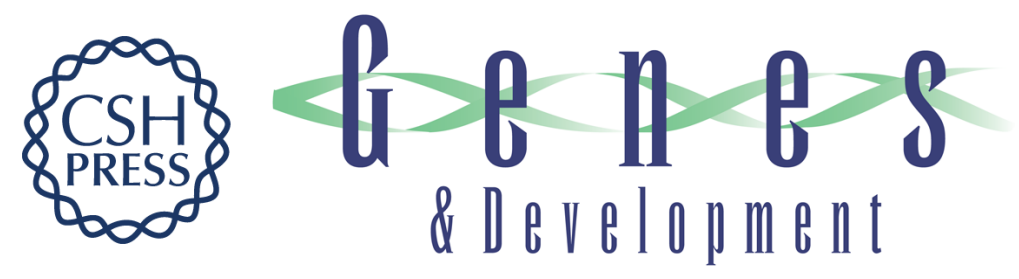

\section{Psidin, a conserved protein that regulates protrusion dynamics and cell migration}

Ji Hoon Kim, Aeri Cho, Hongyan Yin, et al.

Genes Dev. 2011, 25: originally published online March 15, 2011

Access the most recent version at doi:10.1101/gad.2028611

\section{Supplemental http://genesdev.cshlp.org/content/suppl/2011/03/09/gad.2028611.DC1 Material}

References This article cites 46 articles, 13 of which can be accessed free at: http://genesdev.cshlp.org/content/25/7/730.full.html\#ref-list-1

\section{License}

Email Alerting

Receive free email alerts when new articles cite this article - sign up in the box at the top Service 